Cite this: RSC Adv., 2017, 7, 15625

Received 22nd January 2017

DOI: $10.1039 / \mathrm{c} 7 \mathrm{ra00964j}$

rsc.li/rsc-advances

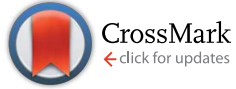

Accepted 27th February 2017

\section{Fabrication and characterization of novel shape- stabilized stearic acid composite phase change materials with tannic-acid-templated mesoporous silica nanoparticles for thermal energy storage}

\author{
Yan Chen, ${ }^{a}$ Xiongjie Zhang, ${ }^{a}$ Beifu Wang, ${ }^{b}$ Mengjiao Lv, ${ }^{a}$ Yingying Zhu $^{a}$ \\ and Junkai Gao*a
}

\begin{abstract}
Tannic-acid-templated mesoporous silica nanoparticles (TAMSNs), which were synthesized using a simple, environmentally friendly, cost-effective, and nonsurfactant-based template method, were developed as a matrix for stearic acid to fabricate a novel shape-stabilized phase change material (SA/TAMSN). The characterization results showed that stearic acid was fully adsorbed on the TAMSNs by physical adsorption and the TAMSNs had no effect on the crystal structure of stearic acid. According to the DSC results, although the TAMSNs had a confinement effect on the activity of the stearic acid molecules, the fusion and solidification enthalpies of SA/TAMSN could reach $108.8 \mathrm{~J} \mathrm{~g}^{-1}$ and $114.1 \mathrm{~J} \mathrm{~g}^{-1}$, respectively. Additionally, the TGA thermograms indicated that there was no apparent weight loss from $20{ }^{\circ} \mathrm{C}$ to $223{ }^{\circ} \mathrm{C}$ for SA/TAMSN, which demonstrated that SA/TAMSNs have excellent thermal stability. All of the results suggested that the TAMSNs could be used as a promising matrix candidate for the shape stabilization of stearic acid.
\end{abstract}

\section{Introduction}

With rapid social and economic development, human's demand for energy is growing, yet sustainable and renewable energy has been followed with strong interest as the energy crisis and environmental problems are becoming increasingly serious. ${ }^{1-3}$ Phase change materials (PCMs) are energy storage materials which can absorb or release a huge amount of heat during the phase change process. ${ }^{4,5}$ Because of their merits, which consist of high energy storage density and environmentfriendly features, PCMs have aroused much attention for their applications in many fields such as the construction industry and transportation. ${ }^{6,7}$

PCMs can be divided into three categories according to the chemical composition of the inorganic, organic and eutectic phase change materials. ${ }^{8}$ Classes of materials which are commonly used as PCMs include paraffins, fatty acids, polyethylene glycols, carbonates, etc. ${ }^{\mathbf{6 , 9}, 10}$ Compared to other investigated PCMs, stearic acid is a fatty acid which has many significant merits, including high heat capacity, appropriate melting temperature range, little or even no supercooling during the phase change process, congruent melting, non-toxic,

${ }^{a}$ School of Port and Transportation Engineering, Zhejiang Ocean University, Zhoushan 316022, China. E-mail: gaojk@zjou.edu.cn; Fax: +86 580 2554491; Tel: +86 580 2554491

${ }^{b}$ School of Naval Architecture and Mechanical-electrical Engineering, Zhejiang Ocean University, Zhoushan 316022, China non-corrosion of metal containers, non-flammability, low vapor pressure, low cost, small volume change and thermal stability. ${ }^{11-13}$ However, there are also some obvious disadvantages of stearic acid, such as leakage and low thermal conductivity, and these drawbacks limit its application. ${ }^{\mathbf{1 4 , 1 5}}$ In order to solve the above mentioned problems, shape-stabilized materials based on porous materials with a three-dimensional network structure as the matrix are introduced to improve the thermal properties of stearic acid.

Many porous materials have been used to immobilize phase change materials, such as olive pomace powder (OPP), active carbon (AC), silica molecular sieves (SBA-15 or MCM-41), and so on. Among these materials, mesoporous silica is very popular as an excellent matrix for PCMs because of its uniform pores, ordered structure and high surface areas, which could ensure that the PCMs fully absorb and refrain from leaking. ${ }^{16,17}$ Wang et $a{ }^{18}{ }^{18}$ synthesized a shape-stabilized PCM of polyethylene glycol confined in mesoporous silica, which achieved significantly better thermal cycling stability than those that are pure. Min et al. ${ }^{19}$ managed to enhance the thermal properties of shape-stabilized PEG composite PCMs with radial mesoporous silica spheres. He et al. $^{\mathbf{2 0}}$ used calcium chloride-assisted and temperature-assisted sol-gel methods to developed shapestabilized $\mathrm{PEG} / \mathrm{SiO}_{2}$ composite materials, and the DSC and TGA data showed that $\mathrm{PEG} / \mathrm{SiO}_{2}$ had the appropriate phase change temperature and good thermal stability to solve the leakage problem of melted PEG. 
However, the traditional preparations of mesoporous silica had the following problems: ${ }^{\mathbf{2 0 - 2 2}}$ firstly, the templating agents used in the synthesis process are mainly surfactants, such as CATB, P123, SL, CATC, which are costly and are toxic in varying degrees; secondly, the typical methods used to remove the templating agent include calcination or solvent extraction. Calcination could damage the structure of the silica and result in the collapse of its skeleton, and the solvent extraction method is tedious and could lead to pollution. Therefore, it is necessary to develop a new template with properties of low cost, non-toxicity and being easy to remove. Recently, Zharov et al. ${ }^{23}$ put forward a expedient way to prepare mesoporous silica materials by using tannic acid as a template. Tannic acid is a glucoside polymer of gallic acid and has multiple phenolic hydroxyl groups. The preparation of mesoporous silica using tannic acid as a pore-forming agent can overcome all of the above shortcomings on account of its traits of being an environmentally friendly non-surfactant and having low cost.

However, to the best of our knowledge, tannic-acidtemplated mesoporous silica has never been used as the matrix for PCMs to fabricate shape-stabilized phase change materials. Therefore, ongoing efforts are necessary for the study of the shape stabilization of PCMs using this new support. Thus, in this work, tannic-acid-templated mesoporous silica nanoparticles (TAMSNs) were synthesized using a simple, environmentally friendly, cost-effective, and non-surfactant template method, and stearic acid was absorbed in the TAMSNs to develop a novel shape-stabilized phase change material (SA/TAMSN). This is the first time the feasibility of utilizing TAMSNs as the matrix for phase change materials has been explored. The characterization and thermal properties of SA/TAMSNs were studied in detail, and the results indicated that the material exhibited enhanced thermal properties, and has great potential for practical applications.

\section{Materials and methods}

\subsection{Materials}

Tannic acid (ACS-grade) was purchased from Alfa Aesar. Tetraethoxysilane (TEOS, AR) and stearic acid were purchased from Meryer, China. Ammonium hydroxide ( $25 \%$ as ammonia, $\mathrm{NH}_{3}$ ) and ethanol were purchased from Tianjin Fengchuan Chemical Reagent Technologies Co, Ltd. All other reagents were of analytical reagent grade and were used without further purification.

\subsection{Preparation of TAMSNs}

The TAMSNs were synthesized by a one-pot method using TEOS as the silica source and tannic acid as the template. ${ }^{24}$ Typically, $544 \mathrm{mg}\left(3.2 \times 10^{-4} \mathrm{~mol}\right)$ of tannic acid was dissolved in $100 \mathrm{~mL}$ of ethanol at ambient temperature, and then $50 \mathrm{~mL}$ of ammonium hydroxide was added into the solution with vigorous stirring for 1 minute, followed by the addition of $0.6 \mathrm{~mL}$ of TEOS. The above mixture was then vigorously agitated for 2 hours, and the precipitates were collected by high-speed centrifugation (4000 rpm). The collected precipitates were washed with water or ethanol to remove unreacted TEOS and tannic acid. After drying, the TAMSNs were obtained.

\subsection{Preparation of SA/TAMSN}

SA/TAMSN was synthesized via physical blending and an impregnating method. Typically, $0.12 \mathrm{~g}$ of stearic acid was dissolved in $15 \mathrm{~mL}$ of ethanol. $0.05 \mathrm{~g}$ of the TAMSNs was then added into the stearic acid solution, and the suspension was stirred at $200 \mathrm{rpm}$ and at $75^{\circ} \mathrm{C}$ for 4 hours. Finally, the mixture was dried at $75{ }^{\circ} \mathrm{C}$ for $24 \mathrm{~h}$ and the as-prepared solid product was denoted as SA/TAMSN.

\subsection{Characterization}

The SEM images of the TAMSNs and SA/TAMSN were obtained using a Quanta FEG 250 scanning electron microscope, FEI, America. The FT-IR spectra of stearic acid, the TAMSNs and SA/ TAMSN were recorded by a Nicolet 6700 transform infrared spectrometer. The X-ray diffraction (XRD) patterns of stearic acid, the TAMSNs and SA/TAMSN were recorded at $40 \mathrm{kV}$ and 40 $\mathrm{mA}$ between $5^{\circ}$ and $100^{\circ}$ with a DX-2700 X-Ray Diffractometer, Thermo Scientific, America. The thermogravimetric analyses of stearic acid and SA/TAMSN were measured at a heating rate of $10{ }^{\circ} \mathrm{C}$ per minute and in a temperature range of ambient temperature to $500{ }^{\circ} \mathrm{C}$, under a high-purity nitrogen atmosphere using a HCT-1 thermogravimetric analyzer, Beijing henven, China. The thermal energy storage properties of stearic acid and SA/TAMSN were obtained by a NETZSCH DSC 200-F3 thermal analyzer, and the specimens were heated and cooled between $0{ }^{\circ} \mathrm{C}$ and $100{ }^{\circ} \mathrm{C}$ at the rate of $10^{\circ} \mathrm{C}$ per minute under high-purity nitrogen as the swap gas.

\section{Results and discussion}

\subsection{Characterization of the SA/TAMSN}

The structure and morphology of the TAMSNs and SA/TAMSN were investigated by using a scanning electron microscope (SEM) and with transmission electron microscopy (TEM), and the images are shown in Fig. 1(a) and (b). As shown in Fig. 1(a), it is indicated that the TAMSNs are spherical and monodisperse particles with rough surfaces. Fig. 1(b) shows that the TAMSNS were a kind of mesoporous material that has a porous structure with certain pores. The formation of the special morphology of the TAMSN particles was mainly attributed to the electrostatic interactions and hydrogen bonding between the silicate species and supramolecular tannic acid. ${ }^{23}$ The protonated hydroxyl groups of tannic acid could undergo hydrogen bond formation with the silicate particles from TEOS, which contributed to the formation of the substantial complex, and then, with the removal of the tannic acid from the complex, the particles connected through reticular formation, and the TAMSN particles with a special morphology were formed. ${ }^{23}$ The SEM images of SA/TAMSN are shown in Fig. 2, and it can be seen that after stearic acid was adsorbed on the mesoporous material; the surface of SA/TAMSN became gelatinous, and the structures of the particles became colloidal and overlapping, indicating that stearic acid was fully adsorbed on the TAMSNs. 

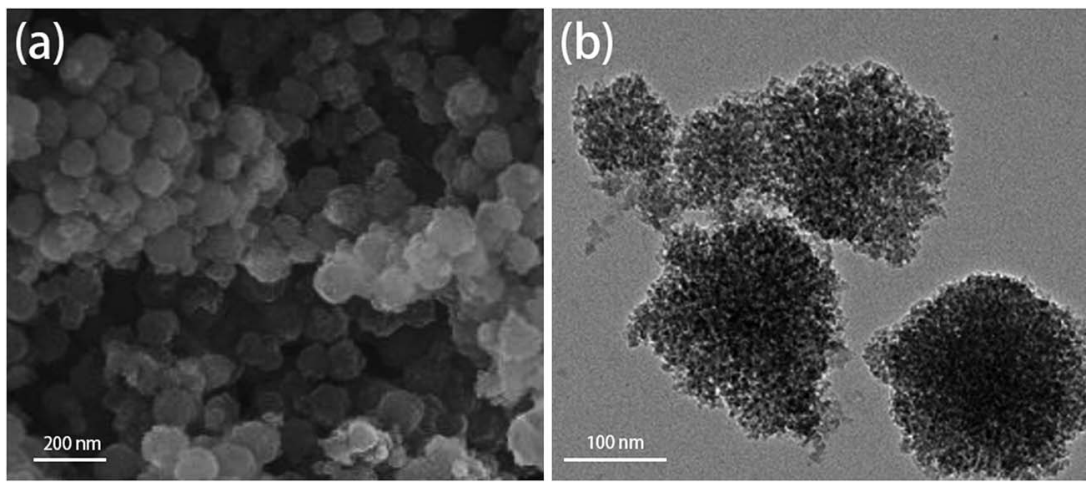

Fig. 1 SEM and TEM images of the TAMSNs

Fig. 3 shows the nitrogen adsorption/desorption isotherms of the TAMSNs, which were found to be typical type IV isotherms and in accordance with the mesoporous material. ${ }^{24}$ The BET specific surface area and BJH adsorption cumulative volume of TAMSN were $471 \mathrm{~m}^{2} \mathrm{~g}^{-1}$ and $0.75 \mathrm{~cm}^{3} \mathrm{~g}^{-1}$, respectively, and the calculated BJH pore size was $8.4 \mathrm{~nm}$. Such pore sizes ensured that stearic acid could enter into the internal structure of the TAMSN and benefit its stabilization.

Stearic acid was immobilized on the TAMSNs by physical adsorption, and SA/TAMSN was characterized using FT-IR spectroscopy. As shown in Fig. 4, for the TAMSNs, the band at $3421 \mathrm{~cm}^{-1}$ was due to the stretching vibration of the hydroxyl groups. ${ }^{25,26}$ The peaks at $1095 \mathrm{~cm}^{-1}$ and $457 \mathrm{~cm}^{-1}$ represented the bending vibration of the $\mathrm{Si}-\mathrm{O}-\mathrm{Si}$ functional groups. ${ }^{27,28}$ These two peaks also could be observed in the spectrum of SA/ TAMSN. Furthermore, in spectrum of pure stearic acid, there were adsorption peaks at $2917 \mathrm{~cm}^{-1}$ and $2849 \mathrm{~cm}^{-1}$ which represented the aliphatic $\mathrm{C}-\mathrm{H}$ vibration. ${ }^{29}$ The peak at 1704 $\mathrm{cm}^{-1}$ was assigned to the characteristic stretching vibration of the $\mathrm{C}=\mathrm{O}$ groups and the band at $1472 \mathrm{~cm}^{-1}$ could correspond to the $\mathrm{C}-\mathrm{O}$ bending peak. ${ }^{29,30}$ Moreover, the peak at $719 \mathrm{~cm}^{-1}$ was assigned to the rocking and bending vibration which is characteristic for aliphatic chains of stearic acid. ${ }^{28}$ These above peaks were all typical for chains of stearic acid, and also appeared in the spectrum of the composite material. In view of these patterns, it could be demonstrated that stearic acid was successfully adsorbed on the mesopores of the TAMSNs by physical adsorption.

Fig. 5 shows the wide-angle XRD patterns of pure stearic acid, the TAMSNs and SA/TAMSN. There was no explicit diffraction peak besides a smooth and broad band between $20^{\circ}$ and $25^{\circ}$ in the wave pattern of the TAMSNs, revealing its highly crystalline structure, and thus its crystallinity could be ignored. In the same range, two conspicuous diffraction peaks were observed in the spectra of both SA/TAMSN and pure stearic acid, indicating that the investigated mesoporous stabilizer TAMSN had no effect on the crystal structure of stearic acid.

\subsection{Thermal properties of SA/TAMSN}

DSC analyses have been used for the measurement of the thermal properties of SA/TAMSN, and the data regarding the heat properties' index of each material were presented in Table 1. As shown in Table 1, pure stearic acid showed an endothermic peak at $73.0^{\circ} \mathrm{C}$ and an exothermic peak at $63.3^{\circ} \mathrm{C}$, with the fusion and solidification enthalpies of $239.4 \mathrm{~J} \mathrm{~g}^{-1}$ and 256.5 $\mathrm{J} \mathrm{g}^{-1}$, respectively. The enthalpy of pure stearic acid was much higher than that of SA/TAMSN with different concentrations, which was the main reason that the mesoporous material could inhibit the phase change activity of stearic acid particles. This was largely due to the fact that some of the stearic acid chains were embedded in the nano-sized pores of the TAMSNs, yet other stearic acid chains were adsorbed on the surface of the
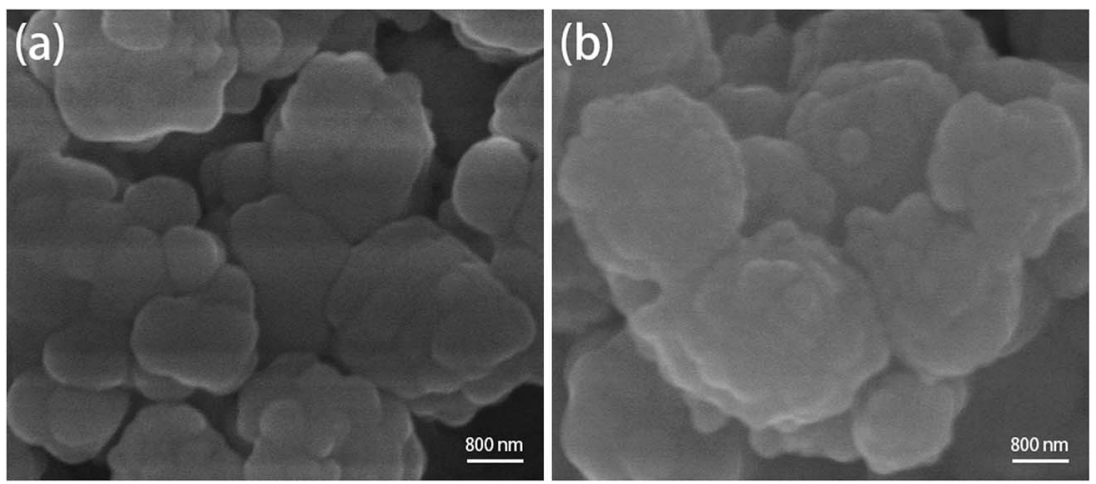

Fig. 2 SEM images of SA/TAMSN. 


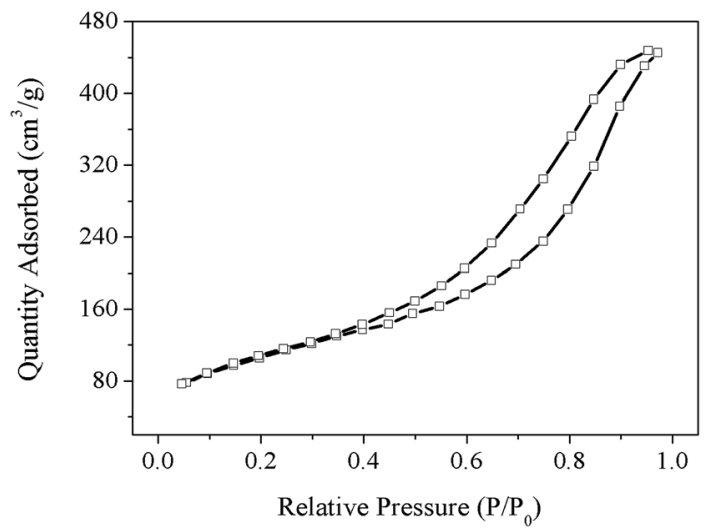

Fig. $3 \mathrm{~N}_{2}$ adsorption/desorption isotherms of the TAMSN.

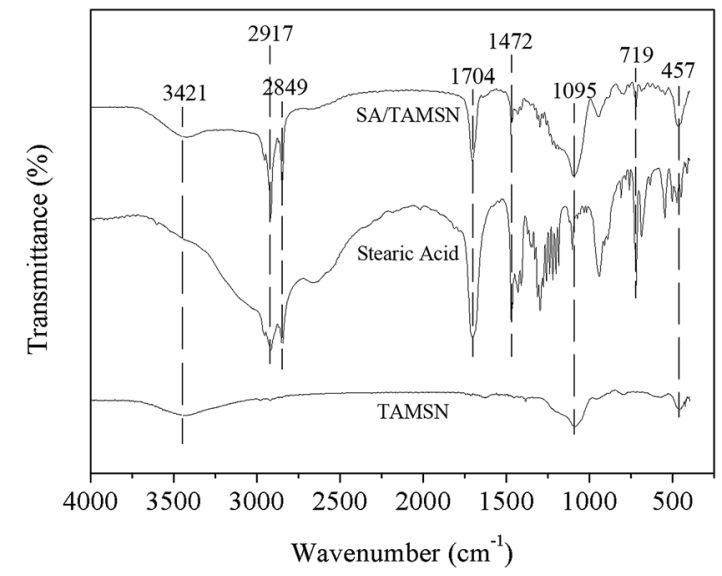

Fig. 4 FT-IR spectra of stearic acid, TAMSN and SA/TAMSN.

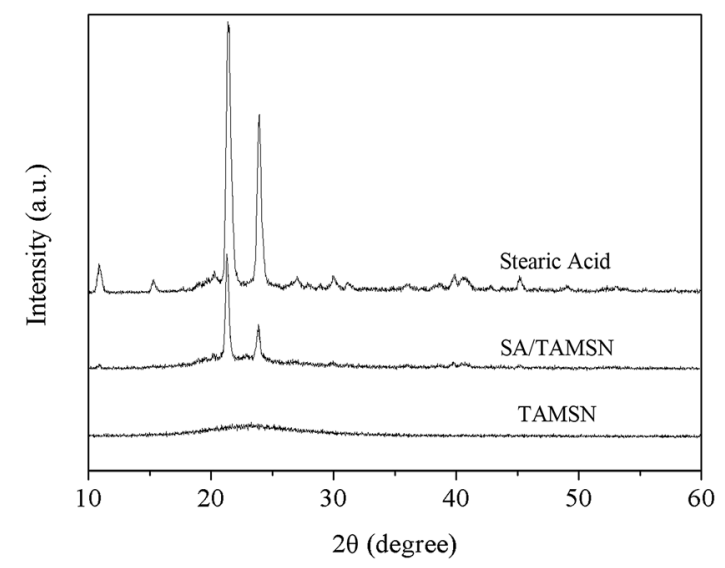

Fig. 5 XRD patterns of stearic acid, TAMSN and SA/TAMSN.

mesoporous matrices. The influence of mesoporous confinement and surface adsorption impeded the crystal aggregation of all of the stearic acid chains, and when the content of the phase change material was $50 \mathrm{wt} \%$, stearic acid could not aggregate to form any crystalline region, which made the enthalpy of $50 \mathrm{wt} \%$ SA/TAMSN close to zero. ${ }^{31-33}$
With the different content of stearic acid in the composite PCMs, it was apparent that the heat enthalpy of each one was significantly different. The composite PCMs with $50 \mathrm{wt} \%$ of stearic acid had little enthalpy because their content of stearic acid was too low to play a role, and the $60 \mathrm{wt} \%$ composite PCMs had fusion and solidification enthalpies of $83.5 \mathrm{~J} \mathrm{~g}^{-1}$ and $81.8 \mathrm{~J}$ $\mathrm{g}^{-1}$, respectively. Compared to these two samples with a lower content of stearic acid, the composite PCMs with $70 \mathrm{wt} \%$ of stearic acid had melting and freezing peak points at $71.5^{\circ} \mathrm{C}$ and $64.0^{\circ} \mathrm{C}$, in relative terms, which were similar to those of the pure PCMs, and the fusion and solidification enthalpies of the $70 \mathrm{wt} \%$ composite PCMs were $108.8 \mathrm{~J} \mathrm{~g}^{-1}$ and $114.1 \mathrm{~J} \mathrm{~g}^{-1}$, respectively, which were lower than that of the enthalpy of pure stearic acid but significantly higher than those of the $50 \mathrm{wt} \%$ PCMs and $60 \mathrm{wt} \%$ PCMs.

The distinctions between DSC data of pure stearic acid and SA/TAMSN with different concentrations could be clearly seen in Fig. 6(a) and (b). The experimental results obtained by differential scanning calorimetry demonstrated that the fabrication of the shape-stabilized phase change material of SA/ TAMSN could prevent stearic acid from leaking during the phase change process. However, the adsorption of stearic acid in the TAMSNs inhibits the activity of the stearic acid molecules, ${ }^{18,37,38}$ and the enthalpy of SA/TAMSN would suffer a massive reduction. Additionally, with the increase of the content of stearic acid in the composite phase change material, the enthalpy of the SA/TAMSN would increase gradually. Furthermore, based on the above comparison data with the other PCMs, it indicated that SA/TAMSN was a fairly effective phase change material.

The fusion and solidification enthalpies of SA/TAMSN were also compared with other shape-stabilized PCMs which also utilized stearic acid as the core material, and are shown in Table 2. It was clear that the performance of SA/TAMSN was competitive, and this was mainly attributed to the matrix TAMSN having a large pore size and a large surface area which could increase the amount of immobilization of stearic acid and enhance the fusion and solidification enthalpies of SA/TAMSN. Moreover, the TAMSNs were synthesized using a simple, environmentally friendly, and cost-effective method, therefore, SA/ TAMSN had a greater potential for practical applications.

\subsection{Thermal stability}

3.3.1 Leakage test. In order to determine the thermal stability of the pure material and the composite PCMs in a high temperature environment, leakage tests of pure stearic acid, the $70 \mathrm{wt} \%$ SA/TAMSN and the $75 \mathrm{wt} \%$ SA/TAMSN were conducted. Specifically, the three samples would be placed in an incubator at $90{ }^{\circ} \mathrm{C}$ for a certain time in order to observe whether the material would leak. For pure stearic acid, a significant melt was observed after 5 minutes at $90{ }^{\circ} \mathrm{C}$, and then, 15 minutes later, about half of the stearic acid sample was melted, which could be seen in Fig. 7(a2). The 75 wt\% SA/TAMSN also observed a slight leakage after 30 minutes, and then, 60 minutes after the start of the experiment, the $75 \mathrm{wt} \%$ PCMs leaked extensively, which could be seen in Fig. 7(c2). Meanwhile, comparing the 
Table 1 Comparison of the thermal properties of the investigated materials based on DSC analysis.

\begin{tabular}{|c|c|c|c|c|c|c|c|c|}
\hline \multirow[b]{2}{*}{ PCMs vs. composites } & \multicolumn{4}{|c|}{ Endothermic process } & \multicolumn{4}{|c|}{ Exothermic process } \\
\hline & $T_{\text {start }}\left({ }^{\circ} \mathrm{C}\right)$ & $T_{\text {end }}\left({ }^{\circ} \mathrm{C}\right)$ & $T_{\text {peak }}\left({ }^{\circ} \mathrm{C}\right)$ & $\begin{array}{l}\text { Fusion } \\
\text { enthalpy }\left(\mathrm{J} \mathrm{g}^{-1}\right)\end{array}$ & $T_{\text {start }}\left({ }^{\circ} \mathrm{C}\right)$ & $T_{\text {end }}\left({ }^{\circ} \mathrm{C}\right)$ & $T_{\text {peak }}\left({ }^{\circ} \mathrm{C}\right)$ & $\begin{array}{l}\text { Solidification } \\
\text { enthalpy }\left(\mathrm{J} \mathrm{g}^{-1}\right)\end{array}$ \\
\hline Pure stearic acid & 65.2 & 74.9 & 73.0 & 239.4 & 67.7 & 58.4 & 63.3 & 256.5 \\
\hline $50 \mathrm{wt} \% \mathrm{SA} / \mathrm{TAMSN}$ & 65.8 & 75.7 & 69.1 & 2.7 & 66.3 & 60.6 & 63.9 & 1.8 \\
\hline $60 \mathrm{wt} \% \mathrm{SA} / \mathrm{TAMSN}$ & 66.7 & 76.8 & 70.5 & 83.5 & 66.3 & 58.7 & 63.8 & 81.8 \\
\hline $70 \mathrm{wt} \% \mathrm{SA} / \mathrm{TAMSN}$ & 67.1 & 78.0 & 71.5 & 108.8 & 66.7 & 59.5 & 64.0 & 114.1 \\
\hline
\end{tabular}
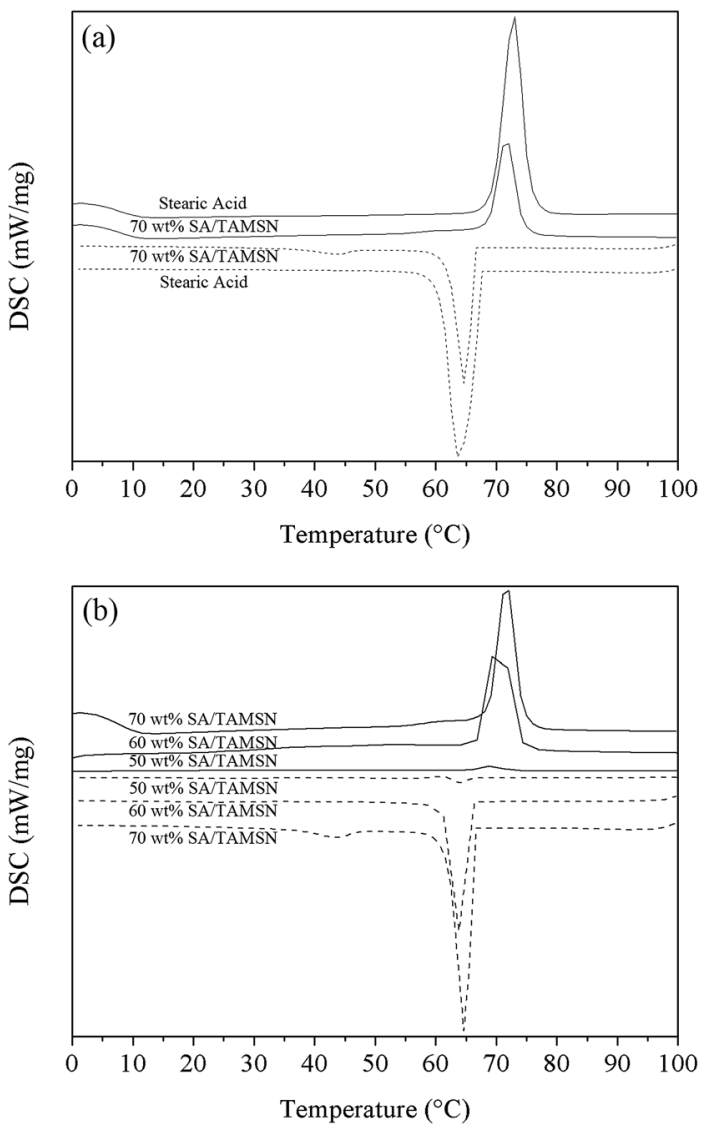

Fig. 6 DSC curves of stearic acid and SA/TAMSN in different concentrations.

experimental results of Fig. $7(\mathrm{~b} 1)$ and (b2), the $70 \mathrm{wt} \% \mathrm{SA} /$ TAMSN did not leak after being heated for 60 minutes. The experimental results illustrated that the TAMSNs can effectively inhibit the leakage of stearic acid. However, with the increase of stearic acid in the composite PCMs, it would be harder for the TAMSNs to inhibit the leakage effectively. Taken together, 70 $\mathrm{wt} \%$ of stearic acid was the best concentration for the preparation of SA/TAMSN.

3.3.2 TGA test. Fig. 8 shows the TGA thermograms of the TAMSNs, pure stearic acid and the $70 \mathrm{wt} \% \mathrm{SA} / \mathrm{TAMSN}$. It is clear that almost no weight loss occurred during heating of the TAMSNs from ambient temperature to $500{ }^{\circ} \mathrm{C}$, which indicated that there was no residual tannic acid in the pores of the TAMSNs. Therefore, the effect of tannic acid on the thermal properties of SA/TAMSN could be neglected. For pure stearic acid and the $70 \mathrm{wt} \% \mathrm{SA} / \mathrm{TAMSN}$, the weight loss processes of both samples were carried out by only one step from ambient temperature to $500{ }^{\circ} \mathrm{C}$. As shown in Fig. 8, no apparent decomposition reaction and weight loss of stearic acid were observed from $20{ }^{\circ} \mathrm{C}$ to $206{ }^{\circ} \mathrm{C}$, and after this temperature range, stearic acid evaporated rapidly with the rise of temperature, until it evaporated almost completely at $327^{\circ} \mathrm{C}$, and only $2.0 \mathrm{wt} \%$ unknown residues remained after the experiment. As for the $70 \mathrm{wt} \% \mathrm{SA} / \mathrm{TAMSN}$, there was no apparent weight loss from $20{ }^{\circ} \mathrm{C}$ to $223{ }^{\circ} \mathrm{C}$, which illustrated that the shape-stabilized PCMs had good heat resistance when the temperature was below $223{ }^{\circ} \mathrm{C}$. As the temperature exceeded $223{ }^{\circ} \mathrm{C}$, the gradual weight loss and the evaporation of most of the core material was indicated. From the temperature of $295{ }^{\circ} \mathrm{C}$, the weight loss rate of the shape-stabilized PCMs became smaller during the experiment, and then, basically stopped at $450{ }^{\circ} \mathrm{C}$. Moreover, the weight loss was $69.2 \mathrm{wt} \%$ for SA/TAMSN. In consideration of the content of stearic acid in the composite PCMs (70 wt\%), the results demonstrated that SA/TAMSN was homogeneous.

Table 2 Comparison of SA/TAMSN with other shape-stabilized PCMs.

\begin{tabular}{|c|c|c|c|c|c|}
\hline PCMs & Melting point $/{ }^{\circ} \mathrm{C}$ & Fusion enthalpy & Freezing point $/{ }^{\circ} \mathrm{C}$ & $\begin{array}{l}\text { Solidification } \\
\text { enthalpy }\end{array}$ & Ref. \\
\hline SA/TAMSN & 67.1 & 108.8 & 66.7 & 114.1 & This study \\
\hline $\mathrm{SA} / \mathrm{GO}$ & 33.3 & 55.7 & 23.0 & 55.9 & Li et $a l^{26}$ \\
\hline $\mathrm{SA} / \mathrm{SIO}_{2}$ & 52.2 & 85.7 & - & - & Zhang et al. ${ }^{35}$ \\
\hline SA/doped-PANI & 52.6 & 84.2 & 53.5 & 83.4 & Wang et $a .^{36}$ \\
\hline
\end{tabular}




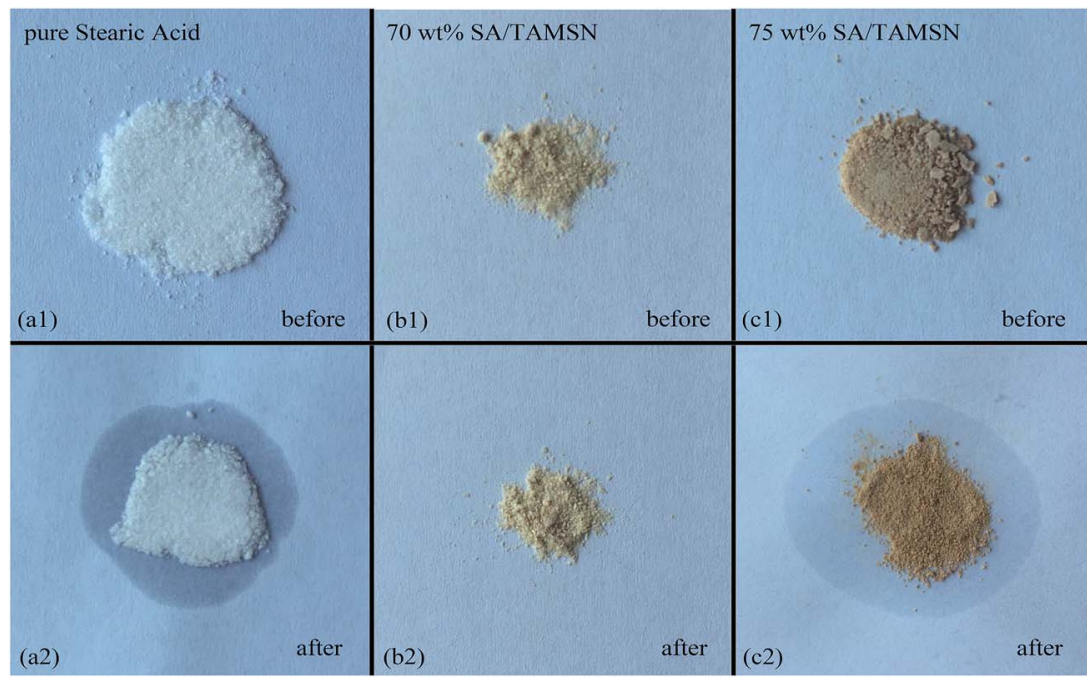

Fig. 7 Leakage test photographs of stearic acid, 70 wt $\%$ SA/TAMSN and 75 wt\% SA/TAMSN.

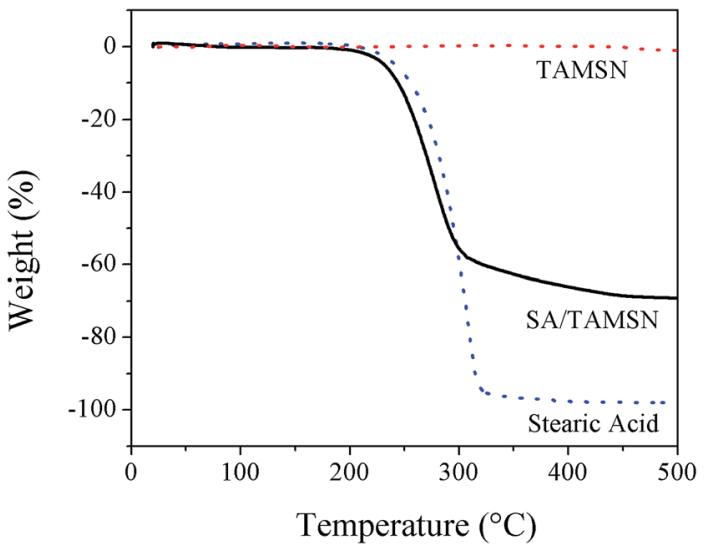

Fig. 8 TGA curves of pure stearic acid and 70 wt $\%$ SA/TAMSN.

\section{Conclusion}

In conclusion, a novel shape-stabilized phase change material (SA/TAMSN) was synthesized, and no leakage of liquid stearic acid from SA/TAMSN was observed when the content of the phase change material was $70 \mathrm{wt} \%$. The DSC results indicated that the melting and freezing peak points of the 70 wt $\%$ SA/TAMSN were $71.5{ }^{\circ} \mathrm{C}$ and $64.0^{\circ} \mathrm{C}$, respectively, which were similar to pure stearic acid, and its fusion and solidification enthalpies were $108.8 \mathrm{~J} \mathrm{~g}^{-1}$ and $114.1 \mathrm{~J} \mathrm{~g}^{-1}$, respectively. According to the results of a TGA experiment, it could be confirmed that the prepared composite PCMs were homogeneous, and would not evaporate below $223{ }^{\circ} \mathrm{C}$, which is a good auxiliary condition for utilization. Besides the good thermal properties of SA/TAMSN, the TAMSNs were synthesized using a simple, environmentally friendly, costeffective, and nonsurfactant template method, and these advantages show SA/TAMSN has great potential for practical applications.

\section{Acknowledgements}

The authors are grateful for financial support by the National Natural Science Foundation of China (No. 51606168).

\section{References}

1 S. Song, L. Dong, Z. Qu, J. Ren and C. Xiong, Appl. Therm. Eng., 2014, 70, 546-551.

2 A. Sharma, A. Shukla, C. R. Chen and S. Dwivedi, Energ. Build., 2013, 64, 403-407.

3 S. K. Song, L. J. Dong, S. Chen, H. A. Xie and C. X. Xiong, Energy Convers., 2014, 81, 306-311.

4 A. Sarı and A. Karaipekli, Sol. Energy Mater. Sol. Cells, 2009, 93, 571-576.

5 L. Shao, A. Raghavan, G. H. Kim, L. Emurian, J. Rosen, M. C. Papaefthymiou, T. F. Wenisch, M. M. K. Martin and K. P. Pipe, Int. J. Heat Mass Transfer, 2016, 101, 764-771.

6 L. Cao, F. Tang and G. Fang, Energ. Build., 2014, 72, 31-37.

7 D. Rozanna, T. G. Chuah, A. Salmiah, T. S. Y. Choong and M. Sa'ari, Int. J. Green Energy, 2005, 1, 495-513.

8 R. Baetens, B. P. Jelle and A. Gustavsen, Energ. Build., 2010, 42, 1361-1368.

9 L. Li, H. Yu, X. Wang and S. Zheng, Energ. Build., 2016, 130, 388-396.

10 R. Baetens, B. P. Jelle and A. Gustavsen, Energ. Build., 2010, 42, 1361-1368.

11 D. Rozanna, T. G. Chuah, A. Salmiah and T. S. Y. Choong, Int. J. Green Energy, 2004, 1, 495-513.

12 A. Sari and K. Kaygusuz, Renewable Energy, 2003, 28, 939948.

13 Y. Yuan, N. Zhang, W. Tao, X. Cao and Y. He, Renewable Sustainable Energy Rev., 2014, 29, 482-498.

14 A. Sarı, A. Biçer and A. Karaipekli, Mater. Lett., 2009, 63, 1213-1216.

15 Q. Guo and T. Wang, J. Mater. Sci., 2013, 48, 3716-3721. 
16 T. Kadoono and M. Ogura, Phys. Chem. Chem. Phys., 2014, 16, 5495-5498.

17 T. Qian, J. Li, H. Ma and J. Yang, Sol. Energy Mater. Sol. Cells, 2015, 132, 29-39.

18 J. Wang, M. Yang, Y. Lu, Z. Jin, L. Tan, H. Gao, S. Fan, W. Dong and G. Wang, Nano Energy, 2016, 19, 78-87.

19 X. Min, M. Fang, Z. Huang, Y. Liu, Y. Huang, R. Wen, T. Qian and X. Wu, Sci. Rep., 2015, 5, 12964.

20 L. He, J. Li, C. Zhou, H. Zhu, X. Cao and B. Tang, Sol. Energy, 2014, 103, 448-455.

21 B. Tang, J. Cui, Y. Wang, C. Jia and S. Zhang, Sol. Energy, 2013, 97, 484-492.

22 B. Tang, Y. Wang, M. Qiu and S. Zhang, Sol. Energy Mater. Sol. Cells, 2014, 123, 7-12.

23 Z. Gao and I. Zharov, Chem. Mater., 2014, 26, 2030-2037.

24 J. K. Gao, L. A. Hou, G. H. Zhang and P. Gu, J. Hazard. Mater., 2015, 286, 325-333.

25 J. Yang, J. Zhang, L. Zhu, S. Chen, Y. Zhang, Y. Tang, Y. Zhu and Y. Li, J. Hazard. Mater., 2006, 137, 952-958.

26 B. Li, T. Liu, L. Hu, Y. Wang and S. Nie, Chem. Eng. J., 2013, 215-216, 819-826.
27 Y. Li, G. Zhou, C. Li, D. Qin, W. Qiao and B. Chu, Colloids Surf., A, 2009, 341, 79-85.

28 Y. Wang, T. D. Xia, H. Zheng and H. X. Feng, Energ. Build., 2011, 43, 2365-2370.

29 D. Mei, B. Zhang, R. Liu, H. Zhang and J. Liu, Int. J. Energy Res., 2011, 35, 828-834.

30 X. Fu, Z. Liu, B. Wu, J. Wang and J. Lei, J. Therm. Anal. Calorim., 2016, 123, 1173-1181.

31 L. Feng, W. Zhao, J. Zheng, S. Frisco, P. Song and X. Li, Sol. Energy Mater. Sol. Cells, 2011, 95, 3550-3556.

32 E. Ahmed and L. Khlid, Carbon, 2005, 43, 3067-3074.

33 X. Py, R. Olives and S. Mauran, Int. J. Heat Mass Transfer, 2001, 44, 2727-2737.

34 F. Tang, L. Gao and G. Fang, Energ. Build., 2014, 80, 352-357. 35 Y. Zhang, Appl. Mech. Mater., 2014, 521, 609-612.

36 Y. Wang, H. Ji, T. Zhang, H. Shi, D. Zhang and H. Feng, Energy Technol., 2015, 3, 734-742.

37 T. Kadoono and M. Ogura, Phys. Chem. Chem. Phys., 2014, 16, 5495-5498.

38 W. Wang, X. Yang, Y. Fang, J. Ding and J. Yan, Appl. Energy, 2009, 86, 1196-1200. 